\title{
Emotional Intelligence among Undergraduate Medical Students at University of Baghdad
}

\author{
Adnan Y. Mohammed \\ Psychiatrist, Ministry of Health, Ibn Rushid teaching hospital, Baghdad, Iraq
}

\begin{abstract}
Objectives: The study aims to assess the level of emotional intelligence among undergraduate medical students and to identify the relationship between the level of emotional intelligence and some demographic variables of the students such as: academic year, gender, residency, and monthly income.

Methodology: A descriptive, cross-sectional design that is initiated for the period of January $1^{\text {st }}$ to May $1^{\text {st }}$, 2018 on a sample consisted of (200) students which was selected by convenient sampling method from four medical colleges at University of Baghdad that are: College of medicine, college of dental medicine, college of pharmacy, and college of nursing. The used questionnaire is divided into two parts; one of them contains the demographic variable of the students and the other one deals with the Scale of Emotional Intelligence (EIS). The data have been collected through the utilization of the self-administrative report as a mean of data collection and analyzed by application of statistical package for social science IBM SPSS (v. 24).
\end{abstract}

Results: The result revealed that student are showing moderate level of emotional intelligence (63.5\%). A relationship was detected between students' gender and his emotional intelligence, while there are no significant relationships between emotional intelligence and academic year, residency, and monthly income.

Conclusions: The study concluded that students at medical colleges group are emotionally stable and emotionally intelligent. There is difference in gender of students with regard to emotional intelligence.

Recommendations: The study recommended for conducting future related studies with various variables and re-conducting the study on a large sample and different specialties is necessary.

Keywords: Emotional Intelligence, Medical Students.

\section{Introduction}

Emotional Intelligence (EI), also called as "Emotional Quotient (EQ)", is one of the most important issues that psychology professionals are concerned with. EI is defined as "the person's capability to make sense, control, and react according to their emotions"(1) Originally, emotional intelligence was recognized as rooted in the concept of social intelligence ${ }^{(2,3, \text { and } 4)}$. More recent, studies provided evidence that the two concepts really defined interrelated components of the same construct $^{(3)}$. Next, this wide construct was accurately referred to as "emotional-social intelligence"(5). Emotional intelligence refers to the human ability of emotional functioning that includes: recognizing, remembering, describing, identifying learning, and feeling, using, communicating, managing, understanding and explaining emotions ${ }^{(6)}$. This emotional information guides in thinking and behavior ${ }^{(7)}$.

Emotional intelligence has an important role in individuals' life and success which is considered as the ability of individuals to manage their emotions and feelings ${ }^{(8)}$. Recently, emotional intelligence has become wide spread and applied in various fields such as: career, education, and personal development ${ }^{(9}$ and 10).

All over the world, individuals are experiencing various emotional experiences, some of them positive and the other negative such as: love, affection, spite and hatred, sadness and happiness, anger and fear, etc. all of these emotional experiences have important role in persons' life because it affect the mental health. Emotional experiences that have been felt by persons 
are the outcomes of assessing the information which include cognitive or received information processing environment, body, memory, to be given for reacting to special practices and conceive action and result that could be received from emotional mode ${ }^{(11)}$.

The individuals that develop their emotional intelligence can become productive and successful at what they do, and they can help others to become more productive and successful also ${ }^{(12)}$.

It is helpful to evaluate emotional intelligence within organization $^{(13)}$. It is expected that undergraduate medical students to be emotionally stable, empathetic to patients, good in advising and counselling the distressed relatives, and a good relations manager with leadership ${ }^{(14)}$.

Recently, the world emotional intelligence is started getting associated with medical profession ${ }^{(15)}$. Emotional intelligence is related to characteristics of the students and their performance at medical colleges, to that a little researches have been conducted. Precisely to state that emotional intelligence help the individual to use his/her capacities, or skills by which he/she can manage themselves, their life, works and other ${ }^{(16)}$.

Focusing on medical professions, especially nursing and medicine are related with a lot of social demands and stress. Hence, the students in these fields need to cope with various stressors of workload and burden from clinical practices during their education ${ }^{(17)}$. These coping abilities require a good mental health. Therefore, the researcher is focusing on the assessment of emotional intelligence as moderator for mental health and to provide a knowledge base for the future researches in this field.

Objectives of the Study: The present study aims to assess the level of emotional intelligence among undergraduate medical students as moderator to mental health and to identify the relationship between the level of emotional intelligence and some demographic variables of the students such as: academic year, gender, residency, and monthly income.

\section{Methodology}

A cross-sectional descriptive study which is started from the January $1^{\text {st }}$ to May $1^{\text {st }}, 2018$; an assessment approach was used to achieve the earlier stated objectives.

The ethical consideration was obtained from the
Research Ethical Committee at College of Nursing in Baghdad University. In addition, informed written consent was took from the students for participation in research .

Another permission was asked from the Deanship of medical colleges involved in current study to facilitates the researcher task in meeting the students.

Four medical colleges at Baghdad university were included in the study which are: College of Medicine, College of Dentist Medicine, College of Pharmacy, and College of Nursing.

A 200 undergraduate medical students were chosen as (non-probability sample) who are studying at the medical colleges, i.e in this sampling method, the students were selected purposively. (50) students were selected for the sample representation from each college. According to Soper ${ }^{(18)}$, so that the anticipated effect size of 0.15 of the sample size, statistical power level of 0.80 , and a probability level of 0.05 ; all were achieved the minimum required sample size would be 54 .

The questionnaire study is designed by researcher and was divided into two parts; one part contains the demographic variable of the students whivh are: college, gender, residence, and monthly income; the other part is contains the Emotional Intelligence Scale (EIS).

EIS was adopted ${ }^{(19)}$ and used for the current study. EIS is consisted of (41) items that cover the emotional intelligence components which represented by four domains in the scale that are: empathy (represented by items 1 - 12), emotion regulation (represented by items 13 -22), interpersonal relationship management (represented by items 23 - 33), and self-management (represented by items $34-41$ ). Each item in the scale was rated into five Likert scale and scored as follow: always (5), almost (4), sometimes (3), rarely (2), Never (1), except the items numbered 16, 18, 20, 21, 22, 36, 37, 38,40 , and 41 that have reverse scores. The emotional intelligence level was calculated by estimating the cut off points of the total mean of scores \& for the scale which is rated into three levels and scores as follow: low $=41-95$, moderate $=96-150$, and high $=151-205$.

The original validity for EIS was estimated by content validity method through seven experts in educational psychology which met the acceptance degree of $(80 \%)$ for the scale items. The original reliability of EIS was achieved by application of Alpha Correlation 
Coefficient and through method of internal consistency, the reliability results were accepted for all domains of the scale $(\mathrm{r}=0.79,0.82,0.70$, and 0.74$){ }^{(19)}$

The self-administrative report was used for data collection. The questionnaire was distributed after taking the permission from the participants.
Statistical package for social science (IBM SPSS Statistics) version 24.0 was used to analyze the data through descriptive and inferential statistical approaches to get the objectives of the study.

\section{Results}

Table 1: Distribution of Sample according to their Demographic Characteristics

\begin{tabular}{|c|c|c|c|c|}
\hline No. & Characteristics & & $\mathbf{F}$ & $\%$ \\
\hline \multirow{5}{*}{1} & \multirow{5}{*}{ Academic year: } & First & 16 & 8 \\
\hline & & Second & 42 & 21 \\
\hline & & Third & 53 & 26.5 \\
\hline & & Fourth & 89 & 44.5 \\
\hline & & Total & 200 & 100 \\
\hline \multirow{3}{*}{2} & \multirow{3}{*}{ Gender: } & Male & 61 & 30.5 \\
\hline & & Female & 139 & 69.5 \\
\hline & & Total & 200 & 100 \\
\hline \multirow{3}{*}{3} & \multirow{3}{*}{ Residency: } & Upper class neighborhood & 107 & 53.5 \\
\hline & & Low class neighborhood & 93 & 46.5 \\
\hline & & Total & 200 & 100 \\
\hline \multirow{4}{*}{4} & \multirow{4}{*}{ Monthly income: } & Insufficient & 6 & 3 \\
\hline & & Barely sufficient & 48 & 24 \\
\hline & & Sufficient & 146 & 73 \\
\hline & & Total & 200 & 100 \\
\hline
\end{tabular}

No: Number, f: Frequency, \%" Percentage

The analysis of the above table is the following: $(44.5 \%)$ of the students are from fourth academic years, who are female students $(69.5 \%)$. Regarding residence variable, the finding shows that more than half of the students are resident in upper class neighborhood (53.5\%). The monthly income variable indicates that more of the students report sufficient monthly income $(73 \%)$.

Table 2: Emotional Intelligence levels among the Students $(\mathrm{N}=\mathbf{2 0 0})$

\begin{tabular}{|c|c|c|c|c|c|}
\hline Emotional Intelligence & Levels & f & $\%$ & M.S & SD \\
\hline \multirow{3}{*}{ Empathy $^{*}$} & Low & 4 & 2 & \multirow{3}{*}{2.80} & \multirow{3}{*}{.448} \\
\hline & Moderate & 32 & 16 & & \\
\hline & High & 164 & 82 & & \\
\hline \multirow{3}{*}{ Emotion Regulation $^{* *}$} & Low & 71 & 35.5 & \multirow{3}{*}{1.73} & \multirow{3}{*}{.607} \\
\hline & Moderate & 112 & 56 & & \\
\hline & High & 17 & 8.5 & & \\
\hline
\end{tabular}




\begin{tabular}{|c|c|c|c|c|c|}
\hline Emotional Intelligence & Levels & f & $\%$ & M.S & SD \\
\hline \multirow{3}{*}{$\begin{array}{l}\text { Interpersonal Relationship } \\
\text { management }^{* *}\end{array}$} & Low & 0 & 0 & \multirow{3}{*}{2.81} & \multirow{3}{*}{.393} \\
\hline & Moderate & 38 & 19 & & \\
\hline & High & 162 & 81 & & \\
\hline \multirow{3}{*}{ Self-management ${ }^{* * *}$} & Low & 1 & .5 & \multirow{3}{*}{2.14} & \multirow{3}{*}{.36} \\
\hline & Moderate & 170 & 85 & & \\
\hline & High & 29 & 14.5 & & \\
\hline \multirow{3}{*}{$\begin{array}{l}\text { Overall Emotional } \\
\text { Intelligence }\end{array}$} & Low & 0 & 0 & \multirow{3}{*}{2.37} & \multirow{3}{*}{.483} \\
\hline & Moderate & 127 & 63.5 & & \\
\hline & High & 73 & 36.5 & & \\
\hline
\end{tabular}

f: Frequency, \%: Percentage, M.S: Mean of score, SD: Standard deviation

$*$ Low $=12-28$, Moderate $=29-40$, High $=41-60$

$* *$ Low $=11-25$, Moderate $=26-37$, High $=38-55$

${ }^{* * *}$ Low $=8-19$, Moderate $=20-31$, High $=32-40$

**** Low=41-95; Moderate: 96-150: High: 151-205

The above table shows that the students have moderate level of emotional intelligence (overall: moderate= $63.5 \%$ ). Regarding the domains of emotional intelligence, they show high empathy (82\%), moderate emotional regulation (56\%), high interpersonal relationship management (81\%), and moderate self-management (85\%).

Table 3: Significant Difference is noticed between Emotional Intelligence of the students and Academic Year (N=200).

\begin{tabular}{|c|c|c|c|c|}
\hline Academic year $\quad$ Emotional intelligence & Low & Moderate & High & Total \\
\hline First & 0 & 10 & 6 & 16 \\
\hline Second & 0 & 29 & 13 & 42 \\
\hline Third & 0 & 33 & 20 & 53 \\
\hline Fourth & 0 & 55 & 34 & 89 \\
\hline Total & 0 & 127 & 73 & 200 \\
\hline
\end{tabular}

df: Degree of freedom, P: Probability level (P-value $\leq 0.05)$

$\chi^{2}$ obs.: Calculated Chi-square, $\chi^{2}$ crit.: Tabulated Chi-square

The above table shows that there is no significant relationship between emotional intelligence among students and their academic year at $p$-value $\leq 0.05$.

Table 4: Significant Difference between Emotional Intelligence and Students' Gender ( $\mathrm{N}=\mathbf{2 0 0})$

\begin{tabular}{|c|c|c|c|c|}
\hline Gender $\quad$ Emotional intelligence & Low & Moderate & High & Total \\
\hline Male & 0 & 45 & 16 & 61 \\
\hline Female & 0 & 82 & 57 & 139 \\
\hline Total & 0 & 127 & 73 & 200 \\
\hline
\end{tabular}

df: Degree of freedom, P: (P-value $\leq 0.05)$

$\chi^{2}$ obs.: Chi-square(Calculated), $\chi^{2}$ crit.: Chi-square (Tabulated) 
The above table demonstrates that there is significant relationship between emotional intelligence among students with their gender at $\mathrm{p}$-value $\leq 0.05$.

Table 5: Significant Difference is noticed between Emotional Intelligence and Residency of the Students $(\mathbf{N}=\mathbf{2 0 0})$

\begin{tabular}{|l|c|c|c|c|}
\hline Emotional intelligence & Low & Moderate & High & Total \\
\hline Upper class neighborhood & 0 & 64 & 43 & 107 \\
\hline Low class neighborhood & 0 & 63 & 30 & 93 \\
\hline Total & 0 & 127 & 73 & 200 \\
\hline$\chi^{2}$ obs. $=1.350 \mathrm{df}=1 \chi^{2}$ crit. $=1.029 \mathrm{P}=0.245$ & & \\
\hline
\end{tabular}

df: Degree of freedom, P: (P-value $\leq 0.05)$

$\chi^{2}$ obs. : Chi-square (Calculated), $\chi^{2}$ crit.: Chi-square(Tabulated)

The above table indicates that there is no significant relationship between emotional intelligence among students with thier residence at $\mathrm{p}$-value $\leq 0.05$

Table 6: Significant Difference between Emotional Intelligence and Monthly Income of the Students ( $=200)$

\begin{tabular}{|l|c|c|c|c|}
\hline Income & Low & Modional intelligence & High & Total \\
\hline Insufficient & 0 & 2 & 4 & 6 \\
\hline Barely sufficient & 0 & 33 & 15 & 48 \\
\hline Sufficient & 0 & 92 & 54 & 146 \\
\hline Total & $\mathbf{0}$ & $\mathbf{1 2 7}$ & $\mathbf{7 3}$ & $\mathbf{2 0 0}$ \\
\hline$\chi^{2}$ obs. $=2.942 \mathrm{df}=4 \chi^{2}$ crit. $=2.840 \mathrm{P}=0.230$ & & \\
\hline
\end{tabular}

df: Degree of freedom, P: Probability level (P-value $\leq 0.05)$

$\chi^{2}$ obs. : Chi-square (Calculated), $\chi^{2}$ crit.: Chi-square (Tabulated)

The above table shows that there is no significant relationship between emotional intelligence among students with their monthly income at $\mathrm{p}$-value $\leq 0.05$.

\section{Discussion}

The analysis of findings in table (1) presented that students were females in fourth academic year who resident in upper class neighborhood with sufficient monthly income. The finding related to academic year may refer that the students in other classes are busy in the schedule of practical training. So, most of their presence is in the areas of clinical training which contribute that more of the sample is in the fourth academic year. The gender-related finding which indicates that most of the students are females may be attributed to the large number of females that registered in medical colleges in which the last statistics about University of Baghdad for the years (2017) and (2018) refers that the number of females students are exceeds the number of male students ${ }^{(20)}$. Regarding residency and monthly income results, the researcher sees that high income families often have better chances for obtaining good education for their sons and daughters, considering that medical colleges group is the highest among other colleges in Iraq. On the other hand, the registration in these colleges requires more costs to meet the requirement of the study. A study found close finding for this study that medical students are associated with average socio-economic status ${ }^{(21)}$.

It has been known out of table (2) that students showing moderate level of emotional intelligence as indicated by the overall score; the emotional intelligence sub-domains refer that the students are highly empathetic and management for interpersonal relationship, while they showing moderate emotional regulation and selfmanagement. The finding of emotional intelligence may 
indicate that students have an emotional maturity and stability that enable them to manage their relationship, evaluate and regulate their emotions. Such finding is depict with the researcher's hypothesis that students at medical colleges having good emotional intelligence. The researcher believes that this emotional maturity is developed among students based on many factors, one of the more important is the nature of the study in these colleges that characterized by their scientific and qualitative content of curriculum that include submission of the students to training and educational programs which requires the student to have personality traits enable him to deal with faculties, other students, and even patients in the clinical area. A study found supportive evidence for this study that found Ozlu et al. who reports that students are showing moderate level of emotional intelligence ${ }^{(22)}$. Many studies also revealed that students who are studying at colleges of health care specialties are showing high scores of emotional intelligence than others (23 and 24).

Table (3) indicated that the relationship between emotional intelligence and academic year among the students is not significant. This finding may reveal that students among all classes of academic years have the same emotional stability and the emotional intelligence has not influenced by students' age group which may be closed with no apparent differences. The current study finding was controversy to many study results such a study that found emotional intelligence is related to academic year and professional success ${ }^{(25)}$.

The finding in table (4) revealed that there is significant relationship between gender and emotional intelligence. Many studies have shown differences in the emotional intelligence between males and females, in which more of these studies reported that females have high emotional intelligence scores $(26,27$, and 28$)$.

In table (5 and 6), no significant relationship have been reported between emotional intelligence with regard to residency and monthly income. Such finding may indicate that most of the students are living in upper class neighborhood and associated with sufficient monthly income. A study found supportive evidence that found those who associated with high socio-economic status having more emotional intelligence ${ }^{(29)}$.

\section{Conclusions}

1. Students at medical colleges group are emotionally stable evidenced by moderate level of emotional intelligence that they show.

2. There is significant relationship between emotional intelligence and gender of students; females are showing high emotional intelligence than males.

\section{Recommendations:}

1. Conducting future related studies with various variables such as academic performance, mental health, and social skills.

2. Re-conducting the study on a large sample and different specialties is necessary.

Financial Disclosure: There is no financial disclosure.

Conflict of Interest: None to declare.

Ethical Clearance: All experimental protocols were approved under the Ministry of Health and all experiments were carried out in accordance with approved guidelines.

\section{References}

1. Emmerling R, Goleman D. EI: Issues and Common misunderstanding [online]. Retrieved from https//:www.eiconsortium.org. 2003

2. Thorndike E. Intelligence and its uses. Harper's Magazine. 1920; 140: 227-235.

3. Salovey P, Mayer J. Emotional Intelligence. Imagination. Cognition and Personality. 1990; 9: 185-211.

4. Goleman D. Emotional Intelligence: Why it can matter more than IQ. New York: Bantam. 1995.

5. Bar-On R. The bar-On Model of emotional intelligence (ESI). Psicothema. 2006; 18: 13-25.

6. Heins S. Emotional Intelligence. Retrieved from https://eqi.org. is my definition of emotional intelligence. 2005

7. Goleman D. Social Intelligence: The new Science of Human Relationship, Random House Publishing Group. 2006.

8. Nejad M, Nejad A. The Relationship between emotional intelligence and mental health education managers in Khoy city of Iran. European Journal of Experimental Biology. 2012; 2(5): 1728-1732.

9. Mohtasham S. Investigate the relationship between emotional intelligence, job satisfaction and mental health workers. A thesis submitted to Azad 
University of Tankabon, Iran. 2009.

10. Sasanpour M, Khodabakhshi M, Nooryan K. The Relationship between Emotional Intelligence, happiness and Mental Health in Students of Medical Science of Isfahan University. International Journal of Collaborative Research on Internal Medicine \& Public Health. 2012; 4(9): 1614-1620.

11. Omarea F. Evaluation of emotional intelligence and coping strategies gifted girl students Secondary schools of gifted and ordinary in Khorramabad city. A thesis submitted to Azad University of Center Tehran, Iran. 2008

12. Serrat O. Understanding and developing emotional intelligence. Knowledge Solutions; 49. Retrieved from https://www.adb.org. 2009.

13. Sharmila G. (2015). Emotional intelligence assessment with special Reference to medical students of Delhi, Anna University, India.

14. Hojat M, Gonnella J, Nasca $\mathrm{T}$, Mangione S, Vergare $\mathrm{m}$ Magee M. Physician empathy definition, components, measurement, and relationship to gender and specialty. Am J. Psychiatry. 2002; 159: 1563-9.

15. Joshia S V, Srivastavab K, Raychaudhuri A. A descriptive study of emotional intelligence and academic performance of MBBS students, Procedia. Social and Behavioral Science. 2012; 69: 2061-2067.

16. Boyatzis R, Goleman D, Raha K. Clustering competence in emotional intelligence: insights from the Emotional Competence Inventory (ECI). Retrieved from https://www.eiconsortium.com. 2000

17. Watson R, Dreary I, Thompson D and others. a study of stress and burnout in nursing students in Hong Kong: a questionnaire survey. International journal of Nursing Studies. 2008; 45(10): 1534-42.

18. Soper D. A-priori Sample Size Calculator [Software] Retrieved from http://www.danielsoper. com/statcalc.2019
19. Al-Alwan A. Emotional Intelligence and its Relationship with Social Skills and Attachment Styles of University Students in Light of Specialization and Gender. Jordanian Journal in Educational Sciences. 2011; 7(2): 125-144.

20. University of Baghdad. Statistics about University. 2019.

21. GorjiAH, Darabina M, Ranjbar M. Emotional and spiritual intelligence among medical students in Iran. Psychiatry Behav Sci. 2017; 9504.

22. Ozlu Z, Avsar G, Gokalp K, Apay S, Altun O, Yurttas A. Comparison of emotional intelligence levels of students receiving education in different fields. Education research International.2016.

23. Beauvais A, Brady N, O'Shea E and Quinn Griffin M. Emotional intelligence and nursing performance among nursing students. Nurse Education Today. 2011;31(4): 396-401.

24. Codier E, Kooker B, Shoultz J. Measuring emotional intelligence of clinical staff nurses. Nursing Administration Quarterly. 2008; 32(1): 8-14.

25. Romanelli F, cain J, Smith K. Emotional intelligence as a predictor of academic and professional success. AM J Pharm Edu. 2006; 70(3): 69.

26. Ajmal S, Javed S, Javed H. Gender differences in emotional intelligence among medical students. International Journal of Business and Social Sciences. 2017; 8(3): 205-207.

27. Arteche A, Chamorro-Premuzic T, Furnham A, Crump J. The relationship of trait EI with personality, IQ and sex in UK sample of employees. International Journal of Selection and Assessment. 2008; 16: 421-426.

28. Bar-On R. Emotional and Social Intelligence Inventory (EQ-I): Technical manual. Toronto, Ontorio, Canada: Multi-health system.2000.

29. Jamadar C, Sindhu A. The impact of soci economic status on emotional intelligence and creativity among tribal adolescent students. The International Journal of Indian Psychology. 2015; 3(1). 